\title{
MELHORAMENTO GENÉTICO DE MAMONA (Ricinus communis L.) VISANDO À PRODUÇÃO DE VARIEDADES ADAPTADAS AO CULTIVO MECANIZADO
}

\author{
Bruno Melegari de Souza Almeida ${ }^{1}$ \\ Robson Luiz Costa dos Santos ${ }^{2}$ \\ Antonio Fluminhan Júnior ${ }^{3}$
}

\section{RESUMO}

Entre as espécies vegetais utilizadas como matéria prima para a produção de biodiesel, a mamoneira (Ricinus communis L), apresenta diversas vantagens, tais como: o elevado teor de óleo em suas sementes, facilidade de cultivo e grande capacidade de adaptação às condições de clima e solos tropicais. O presente trabalho visou a implantação de um programa de melhoramento genético desta espécie, com o intuito de obter cultivares com características agronômicas favoráveis para a produção mecanizada. Os experimentos foram conduzidos no campo experimental da Universidade do Oeste Paulista, em Presidente Prudente-SP, e consistiram de ciclos consecutivos de seleção a partir do cultivar comercial AL-Guarany. Foi empregado o método de seleção recorrente fenotípica, de modo a selecionar plantas com características favoráveis, tais como: baixa estatura, pequeno número de ramificações, pequeno diâmetro do caule, grande número de inflorescências, e elevados teores de óleo em suas sementes. Após três ciclos de seleção foram obtidos 30 genótipos que apresentaram: plantas com estatura inferior a $1,80 \mathrm{~m}$, caule com diâmetro médio inferior $3,5 \mathrm{~cm}$, número médio de quatro ramificações por planta, frutos maduros e indeiscentes, permanecendo nos racemos até a maturidade fisiológica, e teores de óleo em suas sementes atingindo até $46,9 \%$. Os dados obtidos permitem concluir a viabilidade do método de melhoramento empregado. Os resultados foram amplamente favoráveis e podem ter aplicação imediata no setor produtivo, pela relação direta com a produção de biocombustíveis, setor industrial muito promissor na nossa região.

\section{BREEDING OF CASTOR OIL ( Ricinus communis L.) TARGETING THE PRODUCTION OF VARIETIES ADAPTED TO MECHANIZED FARMING}

\footnotetext{
${ }^{1}$ Graduado em Ciências Biológicas - modalidade Licenciatura, Universidade do Oeste Paulista UNOESTE. E-mail: bruno.melegari@hotmail.com

${ }^{2}$ Graduado em Ciências Biológicas - modalidade Licenciatura, Universidade do Oeste Paulista UNOESTE. Email: robsonlcz@yahoo.com.br

${ }^{3}$ Doutor em Genética e Fisiologia Celular, Docente do PPG em Meio Ambiente e Desenvolvimento $\underline{\text { Regional, Universidade do Oeste Paulista - UNOESTE. E-mail: fluminhan@unoeste.br }}$
} 


\begin{abstract}
Among the plant species usually employed for biodiesel production, castor bean (Ricinus communis L), has several advantages, such as high oil content in its seeds, ease of cultivation and high capacity to adapt to soil and climate conditions of tropical regions. This research aimed at the establishment of a breeding program of this species, in order to obtain cultivars with favorable agronomic characteristics for mechanized production. The experiments were conducted in the experimental field of the University of Western São Paulo, in Presidente Prudente-SP, and consisted of consecutive cycles of selection from the cultivar AL-Guarani. Phenotypic recurrent selection method was performed in order to select plants with favorable characteristics, such as short stature, small number of branches, small diameter of the stem, high number of inflorescences, and high oil content in its seeds. After three selection cycles we have obtained 30 genotypes that presented: plant height lower than $1.80 \mathrm{~m}$, an average stem diameter less than $3.5 \mathrm{~cm}$, an average number of four branches per plant, ripe fruit and indehiscent, remaining in racemes up to the physiological maturity, and oil content in its seeds reaching up to $46.9 \%$. The data obtained showed the viability of the breeding method employed. The results were very favorable and may have immediate application in the productive sector, by direct relation to the production of biofuels, a very promising industry in our region.
\end{abstract}

KEYWORDS: Ricinus communis L., Plant Breeding, Cultivars Selection.

\title{
CRÍA DE RICINO ( Ricinus communis L. ) ORIENTACIÓN DE LA PRODUCCIÓN DE VARIEDADES ADAPTADAS A LA AGRICULTURA MECANIZADA
}

\begin{abstract}
RESUMEN
Entre las especies de plantas utilizadas como materia prima para la producción de biodiesel, el ricino (Ricinus communis $\mathrm{L}$ ), tiene varias ventajas, tales como alto contenido de aceite en sus semillas, la facilidad de cultivo y gran capacidad de adaptación a las condiciones climáticas y los suelos tropicales. Esta investigación tuvo como objetivo la implementación de un programa de mejoramiento de esta especie, con el fin de obtener cultivares con características agronómicas favorables para la producción mecanizada. Los experimentos se llevaron a cabo en el campo experimental de la Universidad del Oeste Paulista, en Presidente Prudente-SP, y consistieron en ciclos consecutivos de selección del cultivar comercial AL-Guarany. Se utilizó el método de selección recurrente fenotípica con el fin de seleccionar las plantas con características favorables, como baja estatura, pequeño número de ramas, de pequeño diámetro del tallo, grande número de inflorescencias, y alto contenido de aceite en sus semillas. Después de tres ciclos de selección se obtuvieron 30 genotipos que presentaron: plantas con una altura inferior a $1,80 \mathrm{~m}$, el tallo con un diámetro medio de menos de 3,5 $\mathrm{cm}$, el número promedio de cuatro ramas por planta, frutos indehiscentes, permaneciendo en racimos hasta la madurez fisiológica, y el contenido de aceite en sus semillas que alcanzan hasta el $46,9 \%$. Los datos obtenidos mostraron la viabilidad de método de mejoramiento empleado. Los resultados fueron muy favorables y pueden tener aplicación inmediata en el sector productivo, por relación directa con la producción de biocombustibles, una industria muy promissora en nuestra región.
\end{abstract}

PALABRAS CLAVE: Ricinus communis L., Mejoramiento de Plantas, Selección de Cultivares. 


\section{INTRODUÇÃO}

O biodiesel é um combustível renovável, biodegradável e ambientalmente correto, que apresenta inúmeros aspectos favoráveis, devido ao fato de representar uma possível solução para os atuais malefícios provocados pelo uso indiscriminado de combustíveis fósseis, além de representar um importante substituto ao petróleo, quando as jazidas em exploração começarem a se esgotar no mundo. As principais matérias-prima para a fabricação do biodiesel são: o sebo de origem animal e o óleo extraído das sementes de plantas oleaginosas (mamona, girassol, soja, colza, dendê, entre outras).

A mamoneira (Ricinus communis L.) é uma espécie oleaginosa da família Euphorbiaceae, de origem tropical, com ciclo vegetativo anual e cujo cultivo tem grande importância econômica, gerando inclusive a denominação técnica "ricinocultura". Entre as suas vantagens podem ser listadas: o elevado teor de óleo de suas sementes, a facilidade de cultivo pelos pequenos agricultores e a sua grande adaptação às condições de clima e solos do Brasil (FORNAZIERI, 1986). Entretanto, muitas características da planta ainda precisam se melhoradas, tais como: deiscência das sementes, porte da planta, produtividade, e adequação ao cultivo mecanizado, entre outras, como descrito por Myczkowski et. al. (2007).

Entre a maioria das espécies de oleaginosas normalmente cultivadas no Brasil, EMBRAPA (2004b) destaca que a mamoneira é uma das espécies que apresentam notáveis características agronômicas, tais como maior resistência à seca, ao frio e ao calor, ampla adaptabilidade às diferentes condições edafoclimáticas e seu rendimento é pouco influenciado pela latitude, pela altitude e pelo fotoperíodo. Deste modo, essa espécie é considerada uma opção nos sistemas de rotação e sucessão de culturas nas regiões produtoras de grãos e importante alternativa para a produção de biocombustíveis.

O principal produto da mamona é o óleo extraído de suas sementes, sendo considerado um óleo nobre e de grande versatilidade industrial. Em grande parte, por conter em sua composição grande quantidade de ácido ricinoléico, em média cerca de $90 \%$ de sua composição, com três grupos altamente reativos que, juntos, permitem qualidades específicas à produção de uma infinidade de produtos 
industriais (TORRES, 2006). Este grupo também confere, a este composto, estabilidade e alta viscosidade, possibilitando ser considerado um dos óleos mais viscosos, quando comparado a outros óleos vegetais (BELTRÃO, 2004).

Tais características fazem do óleo de mamona uma excelente matéria prima, podendo ser empregado em diversos setores industriais, tais como: na produção de anticongelantes de combustíveis de avião e espaçonaves, pois em variações bruscas de temperatura não sofre alterações em sua característica (CARVALHO, 1991). Conforme Bonjean (1991), o óleo de mamona possui também baixo ponto de solidificação (de $-12^{\circ} \mathrm{C}$ a $-18^{\circ} \mathrm{C}$ ), e pode ser utilizado no revestimento de poltronas e paredes de avião, uma vez que não queima com facilidade nem libera gases tóxicos, além da sua utilização como componente de lubrificantes, resinas, tintas, cosméticos e medicamentos. Outras aplicações de grande valor econômico do óleo de mamona são a fabricação do nylon e da matéria plástica onde o seu emprego é considerado indispensável (AZEVEDO e LIMA, 2001; FREIRE, 2001). O óleo de mamona também pode ser usado para a produção de biodiesel (PARENTE et al., 2003; EMBRAPA, 2004b; FREITAS e FREDO, 2005).

Pesquisas relacionadas com a mamona remontam desde meados da década de 30, quando foi elaborado pelo Instituto Agronômico de Campinas (IAC) um plano geral de melhoramento da mamoneira. Desde então, várias cultivares foram desenvolvidas, e muitas características agronômicas favoráveis foram selecionadas (FORNAZIERI, 1986). A ricinocultura teve seu auge nas décadas de 40 e 50. Porém, após esta época houve uma significativa queda na sua produção, principalmente pelo fato de que os produtores não dispunham de cultivares homogêneas, o que dificultava muito a colheita uma vez que, devido a estas características, só possibilitavam a colheita manual.

Hoje, a mamoneira tem um papel importante na agroindústria, pois se destaca como produtora de um óleo industrial para a confecção de produtos de alto valor agregado, equivalentes aos derivados de petróleo, mas com custo de produção inferior (FREIRE, 2001; SANTOS et al., 2001; FREITAS e FREDO, 2005; TORRES, 2006). No Brasil, pela própria técnica rudimentar de cultivo, encontram-se misturadas bagas tanto de cultivares mais pobres quanto de mais ricas em teores de óleo, provenientes de um mesmo local de produção. Desde aquelas do grupo 
"Ricinus zanziberensis" que possuíam apenas $30 \%$ de óleo, até as cultivares do grupo "Ricinus sanguineus" que chegavam a conter $66 \%$ de óleo (FORNAZIERI, 1986).

Segundo Vieira e Lima (2001) a ricinocultura apresentou, nos últimos anos, uma queda considerável na produção desta oleaginosa no Brasil em relação aos demais países produtores. Grande parte por problemas econômicos como o baixo preço pago ao produtor que varia de acordo com as oscilações do mercado internacional. Segundo dados da CONAB (2005), o Brasil até o ano de 1981, era o maior produtor mundial desta oleaginosa apresentando uma produção média em torno de 300 mil toneladas, estando na frente de outros grandes países produtores, como Índia e China. Infelizmente, a partir deste ano a cultura desta oleaginosa começou a ser ignorada, acarretando sérios prejuízos à produção nacional. Em termos de produção de mamona, o Brasil atualmente se situa abaixo de países como Índia e China, mas oferecendo, como vantagem, um óleo de alta qualidade, tornando o País mais competitivo (CONAB, 2005). Ainda segundo dados da CONAB (2005), atualmente, a produção de mamona no Brasil se concentra principalmente na região Nordeste, sendo a Bahia o maior produtor nacional (TORRES, 2006).

Conforme Beltrão (2003), o Brasil importava cerca de 30\% de diesel mineral derivado de petróleo, equivalendo a 10 bilhões de litros por ano. Sendo que parte desses gastos com importações poderiam ser utilizadas na produção de óleo de mamona, gerando ocupação para mais de 2,5 milhões de pessoas. Beltrão (2003) e Freitas e Fredo (2005) ainda ressaltaram que o biodiesel oriundo do óleo extraído das sementes da mamona possui maior ação lubrificante e promove maior vida útil dos motores em geral, quando comparado àqueles oriundos de outros óleos de origem vegetal. No que se refere ao seu potencial para a produção de biodiesel, a mamona é considerada como excelente devido ao seu alto teor de óleo (CARNEIRO, 2003).

Segundo dados da EMBRAPA (2004b), o Brasil possui potencial para fornecer mais de $60 \%$ do biodiesel em substituição ao óleo derivado do petróleo consumido atualmente no mundo, sendo que, para se efetivar esta produção, acarretará em um inevitável aumento da produção de espécies vegetais oleaginosas. 
O óleo de mamona apresenta a vantagem de ser o único óleo solúvel em álcool e não necessitar de calor e do consequente gasto de energia que requerem outros óleos vegetais em sua transformação para o biodiesel (FREIRE, 2001; PARENTE et al., 2003). Além disso, Beltrão (2004) ressalta que as plantações de oleaginosas, como é ocaso da mamoneira, servem de cobertura do solo, protegendo contra a erosão, além da possibilidade da incorporação dos resíduos vegetais (hastes, folhas e casca dos frutos), que retornam ao solo. Essa operação proporciona a adição de matéria orgânica ao solo e reciclagem dos nutrientes absorvidos das camadas mais profundas do solo pelas raízes (CARVALHO, 1991; SAVY FILHO, 2005).

Com o programa do governo federal para a produção de biodiesel lançado em 2004, fez-se necessária a realização de pesquisas para a obtenção de cultivares mais produtivas (EMBRAPA, 2004a). Segundo Myczkowski et. al. (2007), a Embrapa realizou o pré-lançamento de uma nova cultivar denominada de BRS Energia, que apresenta potencial de produção de $1800 \mathrm{~kg} / \mathrm{ha}$ em apenas 120 dias com uma altura média de plantas de $1,40 \mathrm{~m}$, sendo que o principal local para utilização a nova cultivar será o semi-árido nordestino. Para os autores, as pesquisas têm como objetivo assegurar a mamona como base do projeto de biodiesel, que além da produção busca atender o lado social. Conforme Myczkowski et. al, (2007), com a seleção massal foi possível obter plantas que através das gerações aumentem a incidência de flores femininas, já que o florescimento feminino é uma característica de alelos dominantes.

Por ser considerado amplamente certo o aumento da demanda por espécies oleaginosas, é necessária a realização de pesquisas para a obtenção de cultivares mais adaptados às diversas regiões agrícolas do Brasil, e que apresentam alta produtividade por unidade de área e um alto teor de óleo em suas sementes (EMBRAPA, 2004a). Em adição, a produção do biodiesel apresenta inúmeros benefícios sociais, econômicos e ecológicos, enquanto geradora de empregos, tanto no campo como em atividades industriais (PARENTE et al., 2003). Além de apresentar um baixo custo de produção, tornando-se economicamente viável, permitindo que pequenos produtores possam investir nessa nova tecnologia de combustível (SANTOS et al., 2001; EMBRAPA, 2004b). 


\section{OBJETIVOS}

Esta pesquisa visa ao desenvolvimento de um programa de melhoramento genético com o objetivo de selecionar cultivares de mamona (Ricinus communis L.) que apresentem características favoráveis para o aumento da produtividade desta cultura na região Oeste do Estado de São Paulo.

Os objetivos desta pesquisa envolvem a seleção de cultivares de mamona adaptadas à região Oeste Paulista, como um ponto de partida para o estabelecimento de um programa de melhoramento genético mais amplo, visando à produção de gerações avançadas que mantenham elevadas frequências das características genéticas dos biótipos idealizados.

As características dos biótipos idealizados consideradas ideais para o cultivo mecanizado e a produção em larga escala, foram as seguintes: a) plantas com porte baixo, em torno de 1,30 e 1,80; b) alta produtividade de sementes; $c$ ) resistência a pragas e doenças; d) caule estreito e com poucas ramificações; e) sementes com alto teor de óleo; f) precocidade; g) frutos indeiscentes e com maturação uniforme.

Pretendeu-se selecionar cultivares de mamoneira que favoreçam o cultivo mecanizado, e que apresentam elevada produtividade, além de proporcionar opções para rotação de culturas, destinadas especialmente para a produção de biocombustíveis, uma vez que a referida região freqüentemente sofre o cultivo indiscriminado de monoculturas por largas extensões de área,

\section{MATERIAL E MÉTODOS}

O material básico para a seleção de cultivares de mamona foi o genótipo mais amplamente cultivado na região, a cv. AL-Guarany 2002, que é distribuída comercialmente no estado de São Paulo pela Coordenadoria de Assistência Técnica Integral (CATI). Após o plantio do material no campo experimental do campus II da UNOESTE (Universidade do Oeste Paulista), as 
plantas foram avaliadas e destas foram selecionadas plantas que se destacaram apresentando características morfológicas mais próximas do biótipo idealizado, tais como: plantas de porte baixo, presença de ramificações, número e tamanho de inflorescências, número de bagas por inflorescência, percentagem de flores femininas, entre outras. Destas plantas foram colhidas suas sementes, visando a multiplicação de uma população superior.

\section{Metodologia de seleção e produção de progênies}

Os trabalhos relacionados com o presente projeto de pesquisa foram realizados através das seguintes etapas: a) plantio dos genótipos mais promissores no campo experimental do campus II da UNOESTE (Universidade do Oeste Paulista) localizado no município de Presidente Prudente (SP); b) análise fenotípica do desempenho agronômico e seleção de progênies dos genótipos mais favoráveis, utilizando como critérios de avaliação as características fenotípicas mencionadas; c) realização de cruzamentos experimentais entre os acessos de germoplasma com desempenho superior, e criação de populações avançadas para seleção de indivíduos mais promissores; d) seleção, identificação e multiplicação dos novos cultivares obtidas através de processo de seleção recorrente fenotípica; e) caracterização das propriedades físico-químicas das diferentes frações de óleo extraído de sementes desta espécie, com o objetivo de produzir um novo parâmetro de seleção de cultivares, bem como avaliar o seu potencial para a produção de biodiesel.

Foram empregados ciclos de seleção recorrente fenotípica, comumente aplicado em espécies alógamas. Os materiais selecionados foram continuamente submetidos à análise bromatológica, para determinação do teor de óleo de cada cultivar. Esta análise também foi considerada um critério de seleção no programa de melhoramento genético das espécies.

Após a pré-seleção do material no campo, os mesmos foram levados ao Laboratório de Sementes da UNOESTE, para a armazenagem segura, onde foi realizada a catalogação das plantas que mais se aproximam do biótipo idealizado para a espécie. Os resultados obtidos a cada ciclo de seleção foram analisados 
estatisticamente através de modelos experimentais pertinentes para cada método de seleção empregado.

\section{Plantio, colheita e beneficiamento do material}

A partir do segundo ciclo de seleção, cada parcela consistiu de uma fileira de $7 \mathrm{~m}$ de comprimento, com 8 plantas possuindo um espaçamento de $1 \mathrm{~m}$ entre cada uma. $O$ espaçamento entre fileiras foi de $1 \mathrm{~m}$, sendo que cada parcela foi constituída por 6 fileiras. Possuindo cada parcela $35 \mathrm{~m}^{2}$ e $1530 \mathrm{~m}^{2}$ de área total de campo plantado. Foram plantadas três cultivares paralelamente uma a outra, formando-se blocos que foram separados por espaços, formando corredores de $2 \mathrm{~m}$, entre cada bloco de 3 cultivares plantadas.

Foram plantadas manualmente duas sementes por cova, possuindo cada cova cerca de $5 \mathrm{~cm}$ de profundidade e adubada com $30 \mathrm{~g}$ de adubo. Como foi realizado o plantio de 2 sementes por cova após 15 dias de emergência da plantas foi realizado o desbaste, para evitar competição entre as plantas. Foi realizado também durante a condução do plantio o desbaste de mamoneiras ao redor da área cultivada, a fim de evitar a polinização dos genótipos selecionados por outras espécies selvagens, evitando a contaminação gênica. O perímetro de segurança estabelecido foi de cerca de $4000 \mathrm{~m}^{2}$, a partir das bordaduras da área cultivada.

As colheitas foram realizadas manualmente, e consistiram de três fases: a colheita propriamente dita, a secagem e o beneficiamento. A colheita foi realizada com a retirada do rácemo da planta manualmente, utilizando tesoura de poda, podão ou quebra do racemo. Depois da retirada, foi realizada a remoção dos frutos do rácemo, utilizando-se pente rústico de pregos ou manualmente, sendo depois transportada para secagem natural somente dos frutos em um piso cimentado por cerca de 5 a 15 dias (SAVY FILHO, 2005). Outra forma de colheita manual foi a retirada do racemo que foi diretamente transportado para secagem natural. A colheita do racemo foi efetuada quando $3 / 4$ dos frutos estavam secos (SAVY FILHO, 2005).

Depois da secagem, os frutos deiscentes liberam naturalmente as sementes, no entanto, pode-se complementar essa fase batendo-se os frutos secos 
com a vara, para apressar a liberação das sementes. Para frutos indeiscentes a abertura dos frutos foi realizada por máquina específica ou descascadoras de amendoim adaptadas para mamona. A secagem não foi necessária, pois os frutos já secaram na mamoneira antes da colheita.

\section{Análise dos teores de óleo}

Amostras de sementes de algumas linhagens selecionadas foram utilizadas para a extração de óleo. Cerca de 2,0 g de cada amostra foram submetidas à extração em aparelho Soxhlet (PREGNOLATTO e PREGNOLATTO, 1985), que se seguiu da seguinte forma: Os balões de $250 \mathrm{~mL}$ foram lavados com sabão neutro e em seguida enxaguados com água corrente e depois com água destilada e deionizada. Após secarem em uma estufa por cerca de 6 horas, cada balão foi pesado e identificado de acordo com o número e nome da amostra. Depois de pesados os balões foram colocados na bateria de extração, cada amostra foi colocada em cartuchos confeccionados com papel filtro e dispostas dentro do extrator Soxhlet. Logo em seguida foi adicionado o solvente orgânico, sendo este o éter de petróleo, por cerca de 4 horas. Os balões foram retirados da bateria de extração e colocados na estufa, para o éter evaporar e restar somente nos balões óleo extraído.

Após a evaporação do éter, os balões foram retirados da estufa e resfriados até a temperatura ambiente e, logo em seguida, pesados, sendo obtido o peso do óleo extraído das sementes de mamona. Com esses dados foram realizados os cálculos de porcentagem de teor do óleo das sementes amostradas. $O$ experimento foi realizado em triplicata e obtido uma média.

\section{RESULTADOS E DISCUSSÃO}

A população original utilizada na presente pesquisa apresentou uma heterogeneidade com relação ao diâmetro do caule e a estatura das plantas, ocorrendo tanto plantas com porte baixo, inflorescências grandes, caules estreito e 
sem ramificações, quanto cultivares que demonstraram porte alto; Inflorescências pequenas, colmos espessos e muitas ramificações. O diâmetro dos caules em mamoneira constitui-se uma medida importante, sendo desejável que as plantas apresentem valores baixos, uma vez que plantas com diâmetros maiores causam problemas na colheita mecânica.

Após cada ciclo de seleção, as plantas selecionadas foram submetidas ao intercruzamento aleatório, e novamente avaliadas individualmente para a seleção da nova população. Após dois ciclos de seleção, foi possível a produção de uma população mais homogênea e cujas características agronômicas foram nitidamente mais favoráveis. A avaliação das características morfológicas mencionadas revelou diferenças significativas em comparação com a população original, indicando que foi possível a produção de uma população mais adaptada ao cultivo mecanizado.

Entre os aspectos mais destacados, ressalta-se: altura das plantas, que foi reduzida de cerca de $2,3 \mathrm{~m}$ para cerca de $1,9 \mathrm{~m}$, diâmetro médio dos caules, que foi reduzido de cerca de $6,5 \mathrm{~cm}$ para $3,5 \mathrm{~cm}$, e a quantidade média de ramificações, reduzida de 4 para 2 (Figura 1).

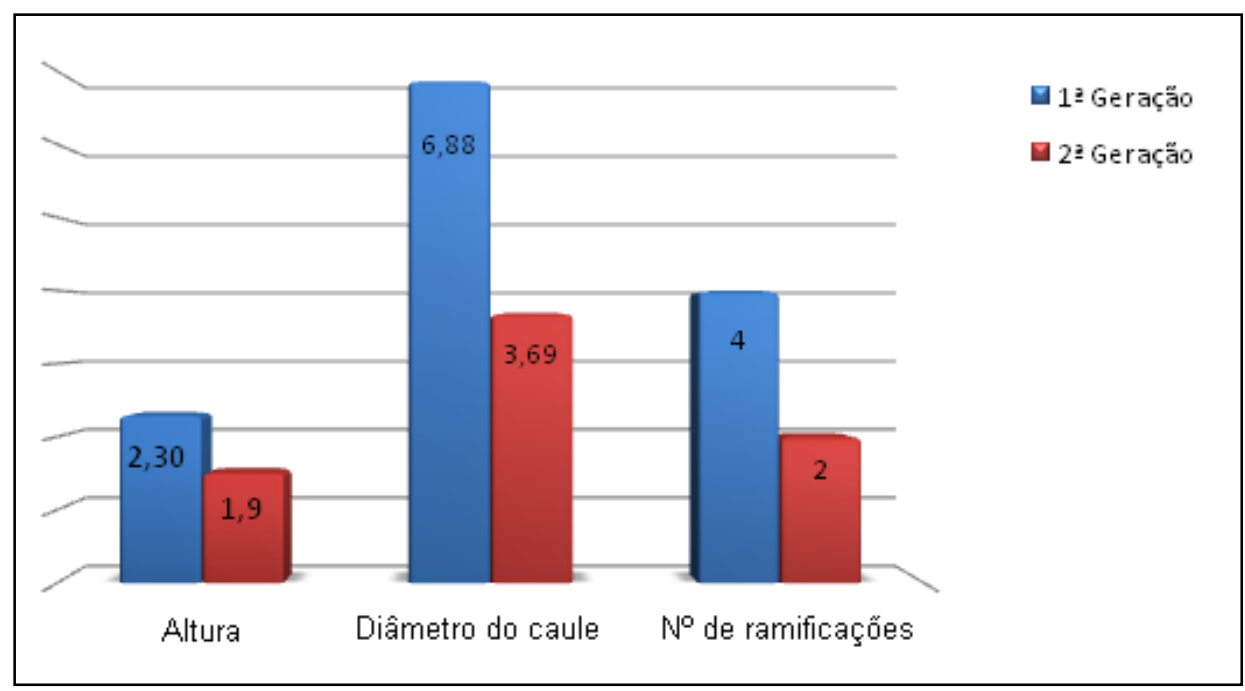

FIGURA 1 - Gráficos indicando as alterações promovidas em algumas características morfométricas, detectadas entre as plantas da primeira geração e da segunda geração de seleção.

Na segunda geração, foram selecionadas 81 plantas que se mostraram vantajosas em relação ao biótipo idealizado, as quais foram submetidas a um novo ciclo de seleção. A partir destas, foram selecionados 30 genótipos resultantes do 
intercruzamento aleatório da população selecionada. Foi realizado o plantio desses 30 genótipos no campo experimental, os quais foram submetidos a uma nova seleção.

Após o terceiro ciclo de seleção recorrente, as plantas dos 30 genótipos selecionados apresentaram características favoráveis ao cultivo mecanizado, tais como: plantas com estatura inferior a 1,80 m, caule estreito com diâmetro médio inferior $3,5 \mathrm{~cm}$, número médio de quatro ramificações por planta, frutos maduros e indeiscentes, permanecendo os cachos secos até o estagio vegetativo final (Figura 2). Dentro de cada genótipo observou-se também outro aspecto importante para cultivo mecanizado: uma grande homogeneidade no crescimento das plantas, tanto 40 dias após a emergência (Figura 3), quanto após 90 dias de cultivo.

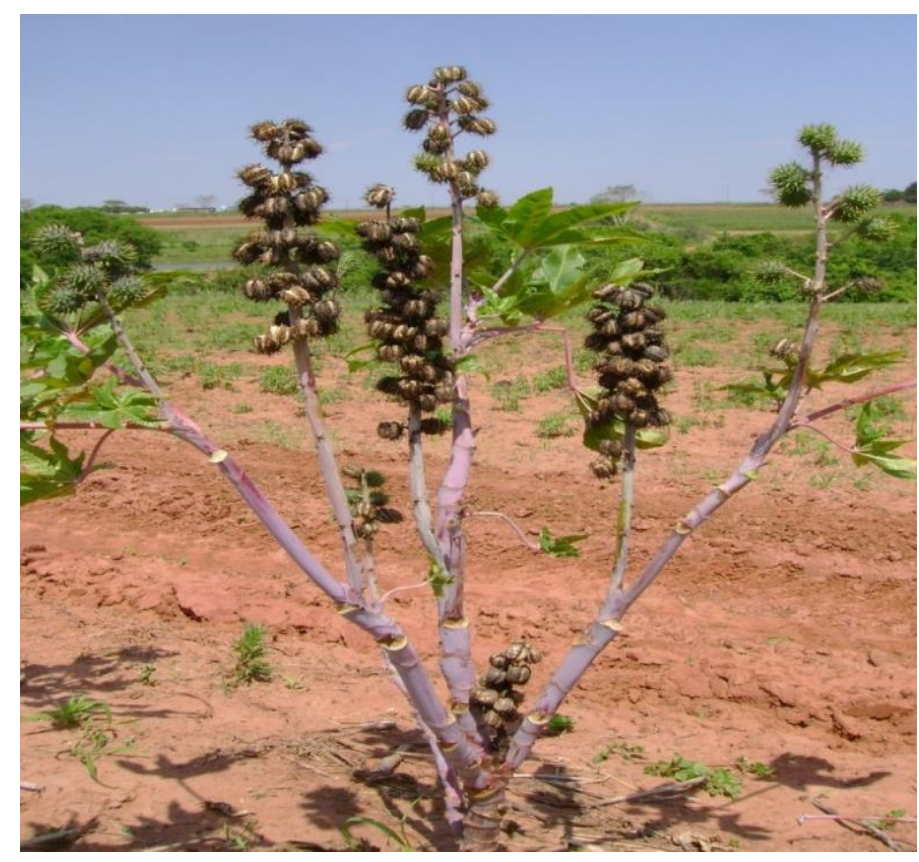

FIGURA 2 - Planta do cultivar 46, demonstrando porte baixo, caule estreito e poucas ramificações, maturação uniforme dos cachos e indeiscência

Fonte: Os autores 


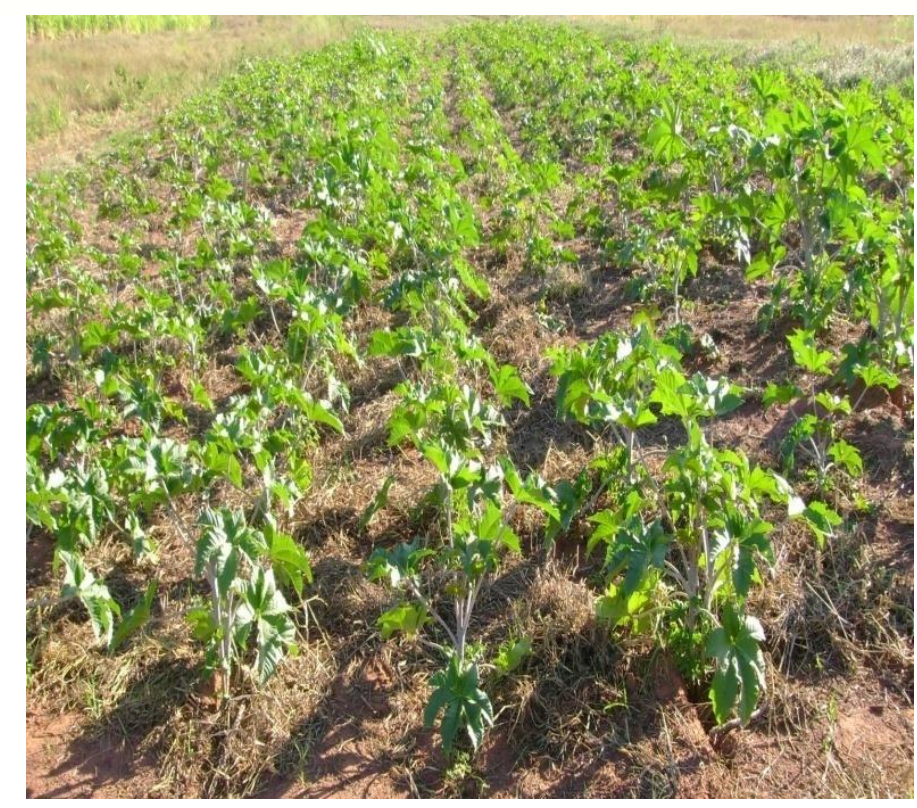

FIGURA 3 - Homogeneidade das plantas no campo após 40 dias de sua emergência.

Fonte: Os autores

Pela análise geral dos caracteres, constatou-se que, após o terceiro ciclo de seleção e intercruzamento, as plantas favoreceram a produção em larga escala. Destaca-se a altura das mesmas, que apresentou um decréscimo significativo em relação à população original, quando as plantas apresentavam média de altura entre $190 \mathrm{~cm}$ e $255 \mathrm{~cm}$, apresentando agora altura variando entre 78 $\mathrm{cm}$ e $130 \mathrm{~cm}$. Alguns cultivares apresentaram o porte de plantas anãs, segundo os padrões estabelecidos pelo mercado (BELTRÃO, 2003). Em adição, os cultivares mantiveram a homogeneidade das plantas no campo e, principalmente, indeiscência dos frutos, que foi mantida mesmo após o terceiro ciclo de seleção.

O teor do óleo das sementes apresentou uma significativa variação, de uma geração em relação à seguinte. Esta variação, de acordo com (SAVY FILHO, 1999), pode ter ocorrido devido à variação climática entre um plantio e o outro. Plantas do segundo ciclo foram plantadas no período de safra, enquanto as plantas do terceiro ciclo foram plantadas na entressafra. Este fator poderá ser melhor avaliado em futuros ensaios de competição com cultivares já estabelecidas no mercado, que também foram melhorados geneticamente.

Houve uma variação de $21,72 \%$ a $46,90 \%$ no teor do óleo das sementes dos 30 genótipos selecionados, ocorrendo uma grande variação entre os mesmos. Enquanto alguns apresentaram grande porcentagem de teor de óleo acima 
de 35\%, ficando dentro dos padrões de mercado (AZEVEDO E LIMA, 2001), outros cultivares ficaram bem abaixo do valor desejável, embora ainda apresentassem características favoráveis ao cultivo mecanizado, como esperado.

\section{CONCLUSÃO}

A partir dos dados obtidos, pode-se concluir que há viabilidade do método de melhoramento empregado na espécie em questão, sabendo-se que os resultados poderão ser ainda ampliados com o avançar das gerações de seleção. Após três ciclos de seleção, já foi possível a produção de uma população homogênea cujas características agronômicas dos materiais selecionados têm sido nitidamente favoráveis, tais como: porte de planta reduzido, número de ramificações pequeno, diâmetro do caule estreito, grande número de racemos por planta, com maturação uniforme e bagas com sementes indeiscentes.

A avaliação das características morfológicas das plantas mencionadas revelou diferenças significativamente superiores em comparação com a população original, indicando que foi possível a produção de genótipos mais adaptados ao cultivo mecanizado. Em adição, foi notado que o teor de óleo encontrado em um dos genótipos selecionados chegou a 46,90\%, superior até mesmo a outras espécies oleaginosas, como o girassol (NUNES et al., 2013).

Os resultados foram amplamente favoráveis e com potencial de aplicação imediata no setor produtivo, pela relação direta com a produção de biocombustíveis, setor industrial muito promissor na nossa região. A realização da presente pesquisa pode representar um importante estímulo para a produção desta espécie vegetal em uma região geograficamente localizada próxima dos principais centros consumidores do biodiesel no Brasil. Finalmente, espera-se que possa contribuir para o fortalecimento da matriz energética nacional, estimulando a produção de outra classe de biocombustíveis, em associação com a crescente produção regional de etanol. 


\section{Periódica Eletrânica \\ Fórum Ambiental}

da Alta Paulista
Volume 11, Número 02, 2015

Campo, Agronegócio

e as Práticas Sustentáveis

\section{REFERÊNCIAS}

BELTRÃO, N.E. de M.; Informações sobre o Biodiesel, em especial feito com o óleo de mamona. Campina Grande: EMBRAPA-CNPA, Dezembro 2003, 3p. (Comunicado Técnico 177).

BELTRÃO, N.E. de M.; O biodiesel do óleo da mamona e a produção de fitomassa: considerações gerais e singularidade. Campina Grande: EMBRAPA-CNPA, 2004, 2p.

BONJEAN, A. Le Ricin. Galileo, France, 1991. Disponível em: http IENICA.NET, castor, p://www.ienica.net/crops/castor.htm, acesso em 12/10/2009.

CARNEIRO, R. A. F. A produção do biodiesel na Bahia. Revista Conjuntura e Planejamento. Salvador, n.112, p.35-43. Setembro, 2003.

CARVALHO, L.O. de. Cultura da mamoneira (Ricinus communis L.). São Paulo: CATI, 1991.17p. FOL3650

CONAB - COMPANHIA NACIONAL DE ABASTECIMENTO. 2005. Mamona. Disponível em: http://www.conab.gov.br. Acesso em: 16 nov. 2014.

EMBRAPA, Centro Nacional de Pesquisa de Algodão (Campina Grande, PB). BRS Paraguaçu e BRS Nordestina: Tecnologia Embrapa para o semi-árido, Campina Grande, 2004a.

EMBRAPA, Centro Nacional de Pesquisa de Algodão (Campina Grande, PB). 0 biodiesel do óleo da mamona e a produção de fitomassa: Considerações gerais e singularidades. Campina Grande, 2004b. Folder.

FORNAZIERI, A.. Mamona: uma rica fonte de óleo e de divisas. 1986. Editora ícone. 152p.

FREIRE, R.M.M. Ricinoquímica. In: AZEVEDO, D.M.P. de; LIMA, E.F. O agronegócio da mamona no Brasil. Comunicação para transferência de tecnologia, p. 295-335, 2001.

FREITAS, S.M. de.; FREDO. C.E. Biodiesel a base de óleo de mamona: algumas considerações. Revista Informações Econômicas, São Paulo, v.35, n. 1, jan., 2005.

MYCZKOWSKI, M.L. et. al. Seleção para aumento da frequência de plantas com maior porcentagem de flores femininas na população FCA planta baixa de mamona. I Congresso Brasileiro de Mamona, 2007.Campina Grande, PB. Disponível em: www.cnpa.embrapa.br/produtos/mamona/puplicacoes/trabalhos cbm1/index.html. Acesso em: 20/ maio/ 2009.

NUNES, B.T. ; PILON, A. ; FLUMINHAN, A. . Avaliação do desempenho agronômico de genótipos de girassol (Helianthus annuus L.) cultivados na região Oeste Paulista e análise do rendimento de óleo, matéria seca e proteína bruta. Fórum Ambiental da Alta Paulista, v. 9, p. 150-165, 2013.

PARENTE, E.J. de S.; SANTOS JUNIOR, J.N.; BASTOS, J.A.; PARENTE JUNIOR., E.J. de S. Biodiesel: Uma aventura tecnológica num país engraçado. Fortaleza: Tecbio, 2003. $66 p$.

PREGNOLATTO, W; PREGNOLATTO, N. P. Normas analíticas do Instituto Adolfo Lutz, Volume 1, Métodos Químicas e Físicos para Analise de Alimentos, 3.a Edição. Secretaria Estadual da Saúde, São Paulo, SP, 1985. 533 p.

SANTOS, R. F. dos.; BARROS, A. L.; MARQUES, F. M.; FIRMINO, P. de T.; REQUIÃO, L. E. G. Análise Econômica. In: AZEVEDO, D.M.P. de.; LIMA, E.F. (eds.). O agronegócio da mamona no Brasil: EMBRAPA-SPI, p.17-35. 2001. 
SAVY FILHO, A. Melhoramento da Mamona. In: Borém, Aluízio. (Org.). Melhoramento de Espécies Cultivadas. Viçosa, MG: UFV, 1999, v., p. 385-407

SAVY FILHO, A. Mamona: Tecnologia Agrícola. Campinas: EMOPI, 2005. 105p.

TORRES, E.A. et al. Biodiesel: o combustível para o novo século. Bahia Análise \& Dados, Salvador, v. 16 , n. 1, p. 89-95, jun. 2006. 